BULLETIN Bulletin hispanique

HISPANIQUE Université Michel de Montaigne Bordeaux

117-1 | 2015

Les poètes des rhéteurs

\title{
Poetas y poesía en el Jardín de la elocuencia de fray José Antonio de Hebrera (primera exploración)
}

\section{Andrea Baldissera}

\section{(2) OpenEdition}

1 Journals

\section{Edición electrónica}

URL: https://journals.openedition.org/bulletinhispanique/3807

DOI: 10.4000/bulletinhispanique.3807

ISSN: 1775-3821

\section{Editor}

Presses universitaires de Bordeaux

\section{Edición impresa}

Fecha de publicación: 1 junio 2015

Paginación: 171-186

ISBN: 979-10-300-0174-7

ISSN: 0007-4640

\section{Referencia electrónica}

Andrea Baldissera, «Poetas y poesía en el Jardín de la elocuencia de fray José Antonio de Hebrera (primera exploración)», Bulletin hispanique [En línea], 117-1 | 2015, Publicado el 01 junio 2018,

consultado el 12 febrero 2022. URL: http://journals.openedition.org/bulletinhispanique/3807 ; DOI: https://doi.org/10.4000/bulletinhispanique.3807 


\title{
Poetas y poesía en el Jardín de la elocuencia de fray José Antonio de Hebrera (primera exploración)
}

\author{
ANDrea BALdissera \\ Università del Piemonte Orientale
}

Consacré au corpus poétique inclus dans le Jardín de la elocuencia de Fray José Antonio de Hebrera (Saragosse, 1677), le présent article met en lumière la dette de l'auteur envers la tradition rhétorique du XVII ${ }^{\mathrm{e}}$ siècle (Gracián, Caramuel, Matienzo, Jiménez Patón) ainsi que l'utilisation qui est faite des citations poétiques par le compilateur.

Mots-clés: Antonio de Hebrera, rhétorique, poésie.

Se pretende analizar el corpus poético incluido en el Jardín de la elocuencia de fray José Antonio de Hebrera (Zaragoza, 1677), para evidenciar sus deudas hacia la tradición retórica del siglo XVII (Gracián, Caramuel, Matienzo, Jiménez Patón) y valorar el uso de las citas poéticas por parte del recopilador.

Palabras claves: Antonio de Hebrera, retórica, poesía.

The article analyses the poetic corpus included in the Jardin de la elocuencia by Fray José Antonio de Hebrera (Zaragoza, 1677), to demonstrate his debt to the Baroque theoreticians - Gracián, Caramuel, Matienzo, Jiménez Patón - and study the use of poetic quotes by the recopilador.

Keywords: Antonio de Hebrera, Rethorics, Poetry.

$\mathrm{E}$ ste artículo podría subtitularse Los poetas de los rétores de los rétores, con cadena de genitivos, porque la obra a la que se dedicarán estas rápidas anotaciones -se trata de la retórica del franciscano José Antonio de Hebrera ${ }^{1}$,

1. Jardin de la eloquencia. Flores que ofrece la retorica a los oradores, poetas y politicos / sacalas ... Fray Iosef Antonio de Hebrera ... religioso de la observancia de N. S. P. S. Francisco ... En Zaragoça : por los herederos de Diego Dormer, [s.a.], pero probablemente 1677, según sugieren tasa, aprobaciones y censuras.

Bulletin Hispanique, Tome 117, n 1 - juin 2015 - p. 171-186. 
que su autor, con no muy rebuscada alegoría, llamó Jardín de la elocuencia ${ }^{2}-$ posee una característica común a muchas recopilaciones retóricas: la de reunir materiales poéticos ya amontonados por otros manuales, que se configuran, por lo tanto, como fuentes indirectas de los textos originales. Afirmación que habrá que matizar, pero fundamentalmente correcta, o así lo creo. Más que buscar rasgos de originalidad en el manual, lo principal será, a mi modo de ver, reconstruir la forma y el proceso de selección del corpus poético insertado en el elocuente Jardín y los enlaces de este con otros libros de raigambre retórica o poética del Seiscientos. Para observar, a la postre, el tipo de producto que sale de la pluma de un teórico de finales del siglo XVII.

Es Hebrera figura de cierto interés dentro del mundo aragonés. Hijo de la villa de Ambel, de noble cepa, fraile menor, fue padre de muchas obras, unas veinte, la mayoría de las cuales de carácter hagiográfico (vidas de santos aragoneses y españoles, pero no solo) o de corte histórico (fue cronista de la Orden en el reino de Aragón). A las que hay que añadir algunos sermones y un par de textos de carácter retórico. En suma, un típico ejemplar de erudito local ${ }^{3}$. El Jardín de la elocuencia, fruto juvenil, forma parte del minigrupo de textos que revelan cierta atención hacia la retórica, o, mejor dicho, hacia la didáctica de la retórica: Latassa y Gómez Uriel recordaban también la existencia de un manuscrito "en cuarto", en el archivo del Real Convento de Predicadores de Zaragoza, titulado Breves noticias del bien hablar .

Félix Monge, que publicó en 1959 una edición del Jardín, subrayaba, en un artículo de $1986^{5}$, algunas expresiones conclusivas de la Oración panegírica, antepuesta al tratado por el franciscano: «es obra para niños que van a las escuelas de gramática, y no le habemos de dar las flores con muchas espinas». Monge (y con él Aurora Egido ${ }^{6}$ lo tomaban bastante en serio, pero posiblemente no

2. Sobre el uso de la imagen y la metáfora del jardín, cf. García Bernal (2007).

3. Cf. Latassa y Ortín (1885: 4), entrada Hebrera y Esmir (Fray Josef Antonio de): «Nació en la villa de Ambel, de una familia noble, a mitad del siglo XVII. Siendo joven de buenas esperanzas, profesó el instituto de san Francisco de la regular observancia en su provincia de Aragón, donde fue predicador general. Definidor, y cronista lo era del reino de Aragón. También obtuvo los cargos de Comisario visitador de la provincia de Compostela y padre de ella, de secretario general de toda su religión y padre de su provincia de Aragón, cuyos conventos había gobernado. En medio de tantos cargos y ocupaciones, era grande su aplicación a todo género de literatura, sin falta alguna en la observancia monástica. Murió en el real convento de san Francisco de Zaragoza el 30 de mayo de 1719». Sigue el listado de las obras en las pp. 4-5.

4. Subtitulado Luces retóricas y epitome de tropos y figuras con ejemplares en prosa y verso, para poetas y oradores, conforme a los maestros clásicos. Dedicadas a Jacinto García de Olbega, infanzón, natural de la villa de Ambel, 1676 (ibid., p. 5).

5. Monge (1986). Parece prometer una nueva edición del texto la ponencia de Jiménez Beltrán (que lamentablemente no pude escuchar) anunciada en el III Congreso Internacional de Jóvenes Investigadores del Siglo de Oro (JISO 2013): «Edición de la obra retórica del Jardín de la Elocuencia (1677) de José Antonio de Hebrera y Esmir».

6. Egido (1986: 35): «Un tratadito para los niños de las escuelas de gramática, como el que Hebrera recoge en su Jardín de la elocuencia, puede servirnos como síntesis del trayecto, con el particular interés de que los argumentos de la elocución de esta retórica tradicional van apoyados con ejemplos de Góngora y otros poetas castellanos. Hebrera paga su tributo elogioso 
haya que leerlo total y exactamente al pie de letra, pese a la indudable índole didáctica de la síntesis retórica de Hebrera. El manual apunta, en realidad, hacia un público un poco más exigente, dotado de mayor conciencia lingüística, algo que se percibe también en los (monótonos) sonetos liminares: hay quien habla de «común utilidad» de la empresa del franciscano, o bien de «enciclopedia»; o incluso de "taller eminente»; sin desdeñar a los que hacen hincapié en los profesionales que podrían sacar provecho de su lectura ("políticos, poetas y oradores / logren con tu Jardín dulce elocuencia»). Nadie se atreve, pues, a definir la obra como un simple compendio escolar.

Huelga decir que la afirmación de Hebrera es, más allá del tópico, una forma de protegerse detrás de cierta falsa modestia: por un lado, va precedida de una serie de párrafos y períodos de ardua complejidad barroca (lo que hacía pensar a Rico Verdú en un autor de escuela culterana, con escasa razón ${ }^{7}$ ), no muy oportunos en un texto supuestamente dirigido a los nińos. Es el mismo alarde de erudición que encontramos en la carta al destinatario, Francisco Antonio de Eguaras y Pasquier, Beaumont y Navarra. Por otro lado, la dedicatoria va seguida por un remate pedagógico de esta clase (que supone un camino entre zarzas, que no espinas):

Por lo que haya faltado, o por poco advertido o por no ser molesto, podrase imitar a Cicerón en el estilo copioso, a Salustio en el breve, a Frontonio [error por Frontino, pero Monge no enmienda] en el seco, a Plinio segundo en el florido, a Heródoto en el dulce, a Tucídides en el grave, a Séneca en el sentencioso, a Filisto en el sucinto, a Teopompo en el acre [...] (fols. d4-d5) ${ }^{8}$.

O sea, un programa de estudios de nivel muy poco infantil. Es claramente un listado convencional, donde se clasifican los estilos por rasgos cualitativos, acompañados por indicaciones bibliográficas (los inalcanzables prosistas clásicos), ejemplares para los fines pedagógicos del buen maestro de retórica. Es exactamente la tónica de la Oración panegírica de Hebrera, quien la presenta a los lectores también como Entrada al Jardín, o sea, Suasoria a la juventud española.

Rebus sic stantibus, lo que queda es que el accessus ad rhetoricam de Hebrera es producto muy digno de atención: un epítome pedagógico, modélico en la dispositio racional de sus partes, aunque no siempre coherente en la elección

a Mnemósine, considerando a la memoria "alma de todo" y medio para que no desmayen los oradores. Según él, la memoria artificial crea un edificio de las artes capaz de albergarlo todo. [...] Aun así el complejo laberinto mnemotécnico no parece servir al predicador de sermones que hará mejor, según Hebrera, en comprender los textos y seguirlos de manera ordenada en las partes de una figura humana, como había hecho con anterioridad Giordano Bruno».

7. Rico Verdú (1973: 140-146). Monge (1966: 380) en cambio: «el culteranismo no se opone al conceptismo. Muy al contrario se inscribe en él [...] como uno de los modos de manifestarse la agudeza».

8. Nótese que el texto concluye así: «Los poetas heroicos, trágicos, épicos, líricos, mélicos y cómicos tienen en la nación española a todo el Parnaso para imitar, en los antiguos mucho que advertir, en los latinos modernos mucho que notar, en la presente obra mucho que corregir» (fol. d5). 
de los modelos, así como desigual en sus secciones, ya que se centra en los ejemplos prácticos bastante más que en la minuciosa exposición de la teoría. Si echamos una mirada al índice y hojeamos el tratado (ya Monge se dio cuenta), sacamos las siguientes conclusiones: se destinan 15 páginas a la Rhetorica, sus orígenes y su esencia (Lib. I); 30 a la Inventio, es decir «las minas para hallar palabras»: los lugares y las fuentes para los varios géneros de elocuencia (Lib. II); 33 páginas son para la Dispositio: el exordium en los tres géneros, la narratio etcétera (Lib III); hay 72 páginas de Elocutio (Lib. IV); y 13 para Memoria, Pronuntiatio y Actio (Lib. V). El más extenso es el cuarto libro: la didáctica de la retórica, que para Hebrera se funda básicamente en la elocutio, con menoscabo de inventio y dispositio (más dependientes de la individualidad de quien usa del arte retórico, que, en cambio, atańe de forma acusada a la elocutio):

Libro IV. Capítulo primero. De la elocución, tercera parte de la retórica [...] La parte más dificultosa de la retórica la llaman; por eso necesita de gran reparo: el inventar, el disponer, dividir, confirmar y confutar a muchas facultades compete, pero el hablar bien solamente al retórico. Este modo de hablar bien con el arte se consigue, pero mejor con el uso y ejercicio, imitando y leyendo las obras de maestros en la oratoria y la poesía. Igualmente han de saber las reglas de la elocución los poetas y los oradores: para todos se pondrán ejemplares (pp. 83-84).

Es este también el libro más poético o rico en citas de poemas y poetas?. Que la elocución pueda encontrar ejemplos y modelos favorables en la poesía no es ninguna novedad (ya Quintiliano lo hacía) ni extraña la cíclica tendencia a la llamada «literarización de la retórica», en este caso favorecida también por la larga presencia, hasta subterránea, del ramismo en España ${ }^{10}$. Es llamativa, sin embargo, la exclusividad de la tipología de ejemplos autoriales sobre todo en un manual que debería formar también a oradores (o sea, predicadores) y políticos. Cuarto y segundo libro (sobre la Inventio) alternan prosa y poesía ${ }^{11}$, pero, a diferencia de lo que pasa con los poetas, cuyas obras va cosechando Hebrera de forma explícita, las muestras en prosa son frases sencillas, anónimas, sin autoridad, que podrían haber salido del tintero del mismo franciscano ${ }^{12}$, con la excepción de raros trocitos de textos sagrados, como, por ejemplo, la segunda

9. Cf. también Galbarro García (2010: 90), que describe así la obra: «Modelos teóricos: Sigue la retórica clásica (Cicerón y Quintiliano), y también a algunos autores coetáneos como Jiménez Patón y Baltasar Gracián. El canon literario: Junto con la Elocuencia en arte de Jiménez Patón esta es la retórica con mayor número de referencias a autores castellanos. El canon lírico está formado fundamentalmente por poetas del siglo XVII; entre los más citados están: Góngora, Lope de Vega y Luis Ulloa Pereira. También cita versos de dramaturgos, entre los que destacan Calderón de la Barca, Tirso de Molina, y Pérez de Montalbán».

10. Martín Jiménez (2004), con amplia bibliografía. Cf. Artaza (2000).

11. El ejemplo poético va introducido o seguido de una explicación u otro ejemplo en prosa.

12. A veces el prototipo en prosa se inspira en el contexto de la misma fuente que proporcionaba los versos: el apartado dedicado a la conduplicación (p. 118) sale de la Elocuencia de Jiménez Patón, donde se propone: «Lope de Vega en su Angélica. Siéntase el rey y el pescador se sienta. Y en otra parte. Mira el peligro, y el consuelo mira» (fol. 83v). Hebrera (p. 118) reproduce la cita y nos hace oír el eco verbal del modelo: «Siéntase el rey, y el pescador se sienta. Cuando se repite dos vezes: ejemplo, Mira, mira tus culpas pecador, mira mira». 
epístola de San Pablo a los Corintios (p. 117) o la dirigida a los Romanos (p. 119). Si cabe, los ejemplos en prosa se corresponden con los dos usos de la elocuencia (demonstrativo y deliberativo), pero no necesariamente. Un ejemplo:

Difinición [...] La tercera [mina para hallar palabras] es notación o nombre de la cosa, del cual se ha de sacar el argumento. Ejemplo: Si el Padre dice amor, ¿cómo conmigo no eres Padre? Otro: Cónsul quiere decir el que aconseja. Luego, si tú no aconsejas lo que a un republicano importa, no eres consul. Para reprehender es eficaz. El segundo Séneca de España lo enseña como el primero: Rey Hijo... Prin. Señor... Rey Mal empiezo / que para estar enojado / es muy amoroso el nombre / Carlos, menos tierno es Carlos (Montalbán, Segundo Séneca de España), (pp. 19-20).

A finales de la ya recordada oración panegírica -llena de trilladas agudezas y de lugares comunes- el fraile aragonés justifica la desbordante presencia de poetas y poemas a través de semejante argumentación:

Un jardín aun a los más tristes alegra, variedad de objetos tendrá en este el lector; por eso he incluido en los ejemplares los versos. Censurarán el desahogo a la religiosa pluma algunos que tengan a la poesía por delito; yo no entiendo que sea delito la poesía. De muchos santos veneramos los poemas. Los padres griegos poietés llamaban a Dios (Caramuel, Rhythmica, fol. 4 ep. 7) en el símbolo de la fe que quiere decir poeta; y ahora leemos Criador, Autor, Edificador. Por eso S. Agustín dijo (Athanasius Kircher, Musurgie, to. 2. lib. 10. reg. 2) que hizo Dios al mundo al modo de un verso, con algunos antítesis, por la variedad de las cosas criadas (fol. d4).

A decir verdad, el Jardín entero, ya desde el subtítulo, Flores que ofrece la retórica a los oradores, poetas y políticos, habla de poesía ${ }^{13}$ (término que hay que entender en su sentido más propiamente técnico, o sea el de texto en versos perteneciente a géneros muy variados, entre los cuales cabe, naturalmente, el teatro).

Finalmente, de las tres citas clásicas que abren el libro, respectivamente de Casiodoro, Aristóteles y Cicerón, la segunda va encaminada Ad eloquentiam poeticam ${ }^{14}$. Pero Hebrera se da cuenta perfectamente de que todo ello le ha llevado a una falta de equilibrio. Así que ruega a los lectores

13. Hasta el punto que, en su aprobación, el padre franciscano Matías Foyas, «lector jubilado, calificador del santo oficio y padre de la provincia de Aragón", afirmaba, retomando con escasa fantasía (y cultura) las autoridades mencionadas ya por Hebrera: «Loables empleos de religiosa pluma, con tanta modestia escritos que aun la poética, que había de ser calumnia, le sirve de calificación, que de esa suerte a nadie es prohibida, pues al mismo Dios se la atribuyen, bien que en metáfora, como escribe Atanasio Kirchero [...] Ordinem seculorum tamquam pulcherrimum carmen ex quibusdam quasi anthitesis, honestavit Deus».

14. En realidad, no se debe al filósofo griego, sino a Averroes, como lo muestra, por ejemplo, el comentario de Benvenuto Rambaldi de Imola (1887: 7) a la magna obra de Dante Alighieri: "Ut enim testatur Aristoteles in sua Poetria: Omne poema et omnis oratio poetica aut est laudatio, aut vituperatio; omnis enim actio et omnis mos non versatur nisi circa virtutem et vicium. Unde Averrois commentator ibidem: Animae nobiles et virtuosae naturaliter adinvenerunt primo artem carminum ad laudandum et efferendum facta pulcra et decora: animae vero deficientes ab his in nobilitate adinvenerunt carmina ad vituperandum et detestandum facta turpia et inhonesta». 
que aprendan primeramente la retórica que enseña el mejor maestro en el Libro de la Sabiduria (46 Sapient.): Antes de hazer elocuente la lengua se ha de cultivar el alma. En los breve campos deste Jardín están repartidas las flores (que aún no puedo llamarlas reglas) [...] ramilletes para oradores, políticos, poetas. Indiferentes están para divinos y humanos fines, el mío es lo primero.

Y avisa a los navegantes de que, si bien "todo es poesía», no todo puede usarse en el gran mar de la predicación, así que el «orador evangélico», para conseguir el buen uso de los estilos, "mediano», "grave» y «sumiso o ínfimo» (que mira a lo sólido del discurso), tendrá que acudir a la bibliografía especializada: «Los ejemplares de los estilos dichos hallará el curioso en Antonio Espeleta, Cassio Longino, Nicolás Causino, Gavilán, Núñez y García en sus retóricas» (p. 93). Al mismo tiempo reconoce los límites de su trabajo:

[...] la mayor desgracia está en el ejercicio. No siempre se ajustan los ejemplares en tropos y figuras al púlpito, ni siempre al consistorio. Señálase el modo para una cosa y el mismo para las demás. No tiene más reglas el soneto que se hace a un Crucifijo que el que pinta las naves: las materias y los objetos solo los distinguen. Por eso, cuando no hallaba que advertir, dejaba en un ejemplar expresados los otros; lo que para los políticos podía notar, lo hallarán que no es apto para los oradores; no con aquella cultura de estilo que requiere un jardín retórico. Pero es obra para nińos que van a las escuelas de gramática, y no les habemos de dar las flores con muchas espinas (p. 31).

Frente a esta neutralidad del tratado, que nunca insiste en el decoro o el respeto del género, se percibe cierta visión autónoma de la palabra poética, donde habrá que sospechar la influencia del obispo Caramuel quien, según veremos, fue una de las fuentes de Hebrera.

Pero, ¿cuál es la tradición versificadora en la que abreva el recopilador? Monge ya lo decía a las claras: los poetas españoles contemporáneos son los preferidos por Hebrera. Sea por la reivindicación de siempre: la lengua y la poesía españolas pueden codearse con la clasicidad, y nótese que casi no se cita ni un verso latino, algo paradójico para quien aconseja acudir a los clásicos (para ser sinceros, los clásicos abundan solamente en la Dedicatoria, con alarde de erudición, y desaparecen en el texto, donde se hallan solo indicaciones bibliográficas y una aislada cita de Virgilio); acaso porque -según añadía el propio filólogo- las particularidades interesantes del Jardín pueden corresponder al ambiente literario de la época y, en parte, a los gustos del autor.

Nos las habemos, al fin y al cabo, con una obra culta, donde sopla cierto aire de lo que tradicionalmente suele definirse como conceptismo, lo que insta (según Monge) a pensar en las prescripciones del gracianismo. A partir de las citas textuales, que incluyen -y, ¿cómo podía ser de otra forma?- a Góngora, pero nada de secuaces y epígonos, como Pedro Soto de Rojas, Bocángel etcétera: el Góngora menos gongorino, el mismo filtrado por Gracián y sus críticas a los imitadores del cordobés.

En cuanto a los ejemplos poéticos seleccionados, el Jardín es obra eclécticoenciclopédica. Donde se enumeran los estilos, asimismo, se ofrece un listado de posibilidades y personalidades bastante estereotipado (pero nótese la 
contemporaneidad de los auctores aquí ensalzados), en paralelo con el elenco inicial de clásicos antiguos:

[...] la dulzura de don Antonio de Mendoza, la propiedad de Lope de Vega, lo terenciano y jocoso d. Agustín Moreto [nunca se citan sus obras]; lo acre d. Francisco de Quevedo; lo lírico d. Luis de Góngora; lo cómico d. Pedro Calderón; lo florido el doct. Montalbán; lo político d. Antonio Solís [no citado]; lo amoroso d. Francisco de Rojas; los demás primores, los poetas españoles que tanto han ilustrado la nación con sus poemas (p. 90) ${ }^{15}$.

A continuación (herencia del gracianismo, de nuevo según Monge), Hebrera critica el estilo hinchado y el excesivo, que se adapta mal a los predicadores:

el hinchado es el insufrible, el de los mal contentos con sus naciones, el de los ladrones de palabras y peregrinos de voces; contra ellos habla Enríquez Gómez, en la Academias morales, en aquel soneto que compone de las voces abultadas, medio latinas y griegas. Don Francisco de Quevedo en la Culta latiniparla; Lope de Vega en el Soneto-diálogo de Boscán y Garcilaso, y el Espejo de la juventud del ilustrísimo Bravo de la Serna, fol. II [...] El cacozelo, parenthyrso o follajudo, el que no cabe en el mundo, todo es hipérboles, comparaciones excesivas, hinchazón de conceptos y tempestad de truenos sin agua; todo es verdores, sin algún fruto: los poetas lo admiten a cada paso, pero del mal el menos, si no llegare a los púlpitos. Montalbán lo usó con especialidad (pp. 90-92).

Lo que no obsta para que el mismo Montalbán, a pesar de todo, sea uno de los poetas más nombrados del Jardín.

Dicho esto, vuelven las preguntas fundamentales: ¿cuáles son las fuentes del aragonés? ¿Y a qué criterios responde la selección de poemas, versos, poetas? Antes que nada, hay que seguir la pista sugerida por Monge: la Agudeza $y$ arte de ingenio de Gracián (uso la edición de Amberes, Jerónimo y Juan Bautista Verdussen, 1669 ${ }^{16}$ ). Lo delatan, además de varios detalles textuales (véase infra), afinidades en el pensamiento sobre los estilos, así como la citada selección de los poemas de Góngora, o el exotismo de algunos anónimos presentados con precisas señas identitarias (el padre jesuita valenciano Pablo de Rajas, "un ingenioso», al que se atribuyen versos de Bartolomé Leonardo de Argensola), y la presencia de Camóes (Ruégoos que me digáis), traducido al español por el mismo Baltasar. En segundo lugar es preciso recordar la Heroyda Ovidiana de Sebastián de Alvarado y Alvear (Burdeos, Guillermo Millanges, 1628), es decir, de Sebastián de Matienzo, cuyas relaciones con la mencionada obra de Gracián ha estudiado Alberto Blecua con detalle ${ }^{17}$. En Matienzo, no solo encontramos muchas citas (con referencias) aceptadas en el Jardín, sino también la clara defensa de los autores modernos. El tercer caudal

15. Hebrera no se exime de preparar también un listado de predicadores-modelos, entre ellos Paravicino (pp. 72-73).

16. Sobre la cuestión de la presencia las letras ibéricas en la antología del jesuita, cf. Pérez Lasheras (2007), y el estudio de Mazzocchi (2015) en este mismo volumen.

17. Blecua (1999); Blecua (2000). Ya se había ocupado del texto, pero superficialmente, Palmer Wardropper (1986). 
de fuentes está constituido por la Elocuencia en arte de Jiménez Patón, con la que el Jardin guarda, a mi entender, relaciones más estrechas de las que parece sugerir Galbarro García (por ejemplo, la Elocuencia es la fuente, declarada en el margen, de las afirmaciones sobre la Digresión en la página 98) ${ }^{18}$; y más con la edición de 1621, ampliada en el Mercurius Trimegistus, sive de triplici eloquentia (Biatiae, Petro de la Cuesta Gallo typographo), que con la princeps de 1604. Finalmente, pero no menos importante que las anteriores, la Rhythmica de Juan Caramuel y Lobkowitz, uno de los tratados de poética y métrica más completos del siglo XVII, segunda parte de esa vasta enciclopedia combinatoria titulada el Primus Calamus, (Ioannis Caramuelis Primus calamus tomus II ob oculos exhibens rhythmicam [...] Editio secunda, Campaniae, ex officina Episcopali, 1668) ${ }^{19}$ y que le proporcionaba a Hebrera cierta visión de la actividad poética y una selección de autores admirables - perfectamente examinada ya por Giuseppe Mazzocchi-, orientada hacia la actualidad y la autonomía de la palabra poética:

La scelta [de los poetas] cade orgogliosamente, oggidianamente, sull'attualità. E, questo, si badi bene, anche se la linea di evoluzione storica (Umanesimo quattrocentista, pertrarchismo garcilasiano, Góngora) è ben presente all'autore che la fissa già nell'Epistola III [...] subito dopo la celebrazione delle glorie ispano-romane [...]. (p. 114) Penso ci sia da interpretare una classificazione [se riefiere a las macrosecciones de la Rhythmica: "Divina», "Mariana», "Coelestia», "Heroica», "Moralia», "Varia»] tanto ideologica [...] come una liquidazione, su quelli che anche fisicamente, oltre che concettualmente, sono i liminari del libro, di una preoccupazione per il contenuto in favore della piena libertà della forma. (p. 118) ${ }^{20}$

De todas formas, del obispo de Vigevano, al parecer, Hebrera fue lector muy atento, ya que pueden rastrearse también huellas de sus pesquisas en otras obras de Caramuel ${ }^{21}$.

18. Galbarro García (2010: 76-77): «En las retóricas escritas en castellano [...] Si por lo general las citas y menciones de autores españoles son bastantes escasas [...], hay dos retóricas en el siglo XVII de las que sí se puede afirmar que establecen un canon literario español, especialmente poético: la Elocuencia en arte de Jiménez Patón [...] y Jardín de la Elocuencia de José Antonio Hebrera y Esmir [...]. Son dos retóricas escritas en castellano, dedicadas a la elocutio en su mayor parte, y ejemplificadas íntegramente con autores en castellano. Pese a los tres cuartos de siglo que las separan, los tres grandes líricos del Seiscientos están presentes, aunque en una proporción distinta: el primer lugar lo ocupa Lope de Vega para Jiménez Patón, y Góngora para Hebrera y Esmir, Quevedo sin embargo aparece representado más secundariamente». Es muy útil el estudio de Rozas López y Quilis (1962: 44-45).

19. El nombre de Caramuel se lee más de una vez en el Jardín, con manifestación de sincera admiración.

20. Mazzocchi (2012).

21. Por ejemplo, un pasaje del Segundo Séneca de España de Montalbán (p. 20 del Jardín) está perfectamente recortado en la Haplotes de restrictionibus mentalibus disputans ... Lugduni, Anisson, 1672, p. 91; o los versos cantados, "Viva la gala dichosa», de la zarzuela El laurel de Apolo de Calderón (Jardín, p. 117, "Anastrophe») se localizan en la p. 145, para explicar la hipérbole; Calderón reaparece con un texto de Ni amor se libra de amor, igualmente presente en la Haplotes. Sin ignorar que este mismo librón, rico en poesía, por ejemplo, traza ya algunos senderos de lectura del teatro aurisecular y cierta visión de Tirso (abundan citas de los Cigarrales). 
A tales repertorios de poesía ya catalogada y ordenada, ça va sans dire, hay que sumar las lecturas y las búsquedas personales de Hebrera. Si es admisible que Hebrera acudiera a ediciones de cancioneros individuales (Josef Navarro, Luis Ulloa Pereira), sin embargo sospecho más probable el uso de otras colecciones de textos poéticos (se me escapa de momento cuáles fueron) o quizás de alguna recopilación (personal o escolar), según sugiere la discontinuidad en las indicaciones al margen, ora demasiado precisas, ora del todo ausentes, si bien Hebrera cita al mismo autor y a la misma obra que parece conocer al dedillo en otras ocasiones.

En efecto, un poco más de la mitad de las citas (un centenar, en total) parece proceder - por lo menos hasta donde alcanzo- de las cuatro 'antologías' antes indicadas, sin exhaustividad y preferencia autoriales (no todo Lope o todo Góngora proceden de una sola fuente, para poner un ejemplo). Para ser más precisos, provienen del cuarteto de fuentes la mayor parte de los textos líricos (cultos cuando menos) y más raramente las muestras teatrales que, en cambio, debieron de seguir pistas alternativas (el 'otro' Caramuel y demás recopiladores) para llegar a la páginas de Hebrera. Asimismo, hay indicios de que el teórico de finales del XVII pescaba también en aguas geográficamente muy cercanas, entre los escritores orientales (Josef Navarro, Juan de Yagüe, Diego Pascual, «maestro de latinidad de la villa de la Almunia», José Gracián Serrano y Manero; los dos últimos son también autores de sonetos paratextuales para el Jardín) ${ }^{22}$.

Normalmente no se hallan en el tratadito, en las divisiones sobre figuras retóricas, juicios sobre la calidad de los poetas o los poemas, porque la ejemplificación se ofrece a secas, dándole relieve, de vez en cuando, a indicaciones prácticas sobre el ámbito (métrico o genérico) de uso de ciertas figuras ("Inducción [...] En las comedias hay muchos ejemplares», p. 132; «Similiter cadens [...] En los versos no se usa, sino en los pareados», p. 124) o las costumbres retóricas de los poetas ("Frecuentación o congeries [...] La Arcadia de Lope y muchos romances la usan», pp. 136-136; "Ironía [...] es un modo de hablar hipócrita [...] Góngora, Quevedo y Moreto lo usan de ordinario», p. 141). Las únicas excepciones son las del libro II, donde en las pp. 22, 26 y 27, se distinguen alabanzas reservadas respectivamente a Góngora («Príncipe de los líricos [...]; Admirablemente el cordobés»), Antonio de Mendoza («Míralo en el dulce Mendoza») y Lope («Admira los efectos de la mujer en este gran soneto del Fénix cómico»).

Antes de ponernos a valorar la aportación del fraile aragonés, es indispensable detenerse un poco sobre un problema de naturaleza filológica, conectado con el de las fuentes. Las series de ejemplos poéticos que se encuentran ya en los cuatro volúmenes evidentemente conocidos por Hebrera, ¿descienden todos directamente de allí? En la mayoría de los textos no se detectan apreciables

22. Pero pueden hallarse consonancias temáticas también entre estos (al parecer) excerpta: después del cuarteto "Aquel que oyó Manzanares», del Romance a un ruiseñor enfermo (de Paravicino), se lee la seguidilla «Era yo por lo negro», insertada en el romance (de Josef Navarro) Encarece la flaqueza en que lo puso la enfermedad (p. 97). 
diferencias entre la forma textual (lo que no prueba en absoluto la dependencia, ni tampoco la niega), pero en algunos se dan variantes, desde las más triviales (se añade una conjunción copulativa) hasta las más relevantes (se reformulan sintagmas). Se trata de un reducido manojo de citas $^{23}$, bastante significativas, que corroboran la hipótesis antes planteada y hablan en favor de las fuentes mencionadas, junto con indicios de otra clase, como algunas coincidencias en las referencias bibliográficas a latere (donde las hay ${ }^{24}$ ). Pueden aducirse algunos ejemplos: en la p. 120, al recordar los "epítetos de la ira», se transcribe el verso de Bartolomé Leonardo de Argensola "cuya tierra y planta hermosa», en lugar de la lección correcta "cuya tierna planta hermosa» (la conjunción copulativa es una patente tentativa de enmendar la lección incorrecta que recabó de Gracián: "cuya tierra planta hermosa»); análogo tratamiento encontramos en el primer verso de un romance de Carrillo y Sotomayor, «Mas si es cierto no consume» (Obras, Madrid, Luis Sánchez, 1613), que pasa a "Y si es cierto no consume» en la Agudeza, para terminar en el Jardín (p. 131) como "Es cierto que no consume» (se explica muy bien, al desaparecer la conjunción $y$ inicial, gráficamente débil). Todo esto induce a postular una técnica de recopilación bastante rigurosa, raramente plagada por errores (de imprenta, y mínimos), pero a veces enmendadora, sin descartar, en otras circunstancias, la contribución de una memorización y de apuntes no necesariamente ejemplares ${ }^{25}$.

Las citas de poetas (célebres, menores o anónimos) pueden observarse desde perspectivas muy distintas. Por ejemplo, es interesante estudiar de qué 'antología' proceden las citas y si se respeta la función que las mismas desempeñaban en su fuente, para acabar con los autores que se merecieron figurar en el desfile hebreriano, frente a los que se vieron excluidos. No menos interesante, según creo, es la selección de los géneros métricos y literarios, operada por el fraile aragonés ${ }^{26}$.

23. Las principales variantes las encontramos en un pasaje de la Dorotea de Lope que no se corresponde a ninguno de los testimonios de la obra que he podido consultar: «¿Cómo compones? Leyendo / y lo que leo imitando [...]» presenta aquí variantes, de tipo oral: «a lo que leo imitando / de lo que imito escribiendo / de lo que escribo borrando / de lo que borro escogiendo». La Rhythmica de Caramuel queda como fuente más próxima (pero con lecciones canónicas: "y lo que leo.../ "y lo que... imito») y la presencia ahí de una variante detectable como error (compongo por componéis) insinúa la duda sobre la posibilidad de una reconstrucción mnemónica por parte de Hebrera.

24. Ej. «Mira de Mescua com. Ing. y Muger» (p. 97) < «Ing. y Mug. Mirademesc. Terc.», Heroyda ovidiana, p. 144. También la clasificación «Un ingenioso» (p. 100) procede de Matienzo («un ingenioso poeta», p. 5) donde la octava de Antonio Mira de Amescua (de la Fábula de Acteón y Diana) incluye ya la variante "que de engañosos ramos transformado" por "quedó en ganchosos ramos transformado». Cf. también la nota 11.

25. El soneto de Jerónimo de Mota, procedente de la Agudeza, titulado Celos, de quien bien ama, amargo freno posee errores, quizás de transcripción y, en todo caso, debidos a la tendencia a uniformar: ej. tiniebla que se opone al sol sereno > al mar sereno, v. 8; Vuelve al infierno ya, dejad mis males $>$ Id al infierno, v. 12 .

26. Blecua (1999: 34) nos recuerda: «Si Jiménez Patón se interesaba solo por el Lope culto -el lírico y épico-y el P. Vitoria por el mitológico -el de la Rimas y la Arcadia- el P. Matienzo, contra todo pronóstico dada su condición de jesuita, escoge la mayoría de los ejemplos, habitualmente 
La Agudeza suministra 17 ejemplos, 15 la Rhythmica, 17 la Heroyda Ovidiana y 10 la Elocuencia en arte. Digo, desde ahora mismo, que las citas se recontextualizan a menudo, pero en los modelos (o en sus sectores) más propiamente retóricos y sistemáticos, como la Agudeza, la Elocuencia patoniana, y a veces la Rhythmica, se distinguen claramente mini-bloques de citas halladas en determinadas zonas de los textos-fuente ${ }^{27}$.

Lo que supone, en general, una lectura libre y selectiva de las fuentes, para filtrar ejemplos independientemente de su contexto original, cuya disposición e ideología pueden aprovecharse cuando toca. Como es natural, una cita del Arte cómico de Lope, en el largo discurso sobre los estilos (p. 85 ${ }^{28}$ ), tiene valor solo por su contenido y contexto primitivo (en la Rhythmica); por eso, adquiere relevancia, pero normalmente la ejemplificación sigue criterios formales. Del examen estructural del Jardín se desprende también que el segundo libro, sobre la Inventio (y esto no maravilla para nada), se alimenta sobre todo de poetas inmortalizados por Gracián en la primera parte de su tratado, sobre la agudeza simple, mientras que el eclecticismo de Caramuel proporciona materiales para varias divisiones a lo largo de libro. Jiménez Patón se asoma más frecuentemente en la parte final del cuarto libro, sobre tropos y figuras (v. la nota 26), a la par que la Heroyda, sin que ello impida, con todo, la aparición aislada de piezas poéticas procedentes de estas obras también en otras secciones hebrerianas (sinécdoque, metáfora etcétera).

No podrán faltar ciertas preferencias en la recuperación de las auctoritates salvadas por Hebrera: Góngora, según comentaba, es prevalentemente cosecha de la Agudeza y de la Elocuencia, mientras que el príncipe de Esquilache y Paravicino se remontan normalmente a Caramuel, quien facilita textos de Calderón en la Haplotes; Lope se extrae de Caramuel, pero aún más de la

sonetos de las comedias sin reparar en que se trata de pasajes más deleitables -infinitamente másque útiles. Su antítesis es Gracián que tanto en el Arte de ingenio como en la Agudeza procura presentar un Lope poeta sacro».

27. Solo algunos ejemplos: en la p. 22, los apartados sobre semejanza y contrariedad reproducen citas de las secciones semejanza y disparidad de la Agudeza (Discursos IX y XXXVI, respectivamente). Lo mismo pasa con los versos que ilustran la conduplicación (p. 118), tomados de la análoga sección de la Elocuencia de Patón (fols. 82v-83r); dos poemas sugeridos por Jiménez Patón (Ya dijimos arriba el fiero estrago y un trocito de las Lágrimas de Angélica de Barahona de Soto) se lucen en las páginas 102-103, justificados por la clasificación retórica (el plural majestatis y un aspecto de la sinécdoque, lo cierto por lo incierto; fols. 82v-83r), así como los de Góngora (Yace debajo de esta piedra fría), Miguel Sánchez (Melisendra está en Sansueña) y Luis Zapata (del Carlos famoso), de las pp. 141-142, están en los fols. 115r-118r de la edición del almedinense. Añado también que los poemas de Góngora, Lope, Salinas y Pedro Soria, colocados en el segundo libro del Jardin (pp. 21-28), se han 'robado' al Gracián de los Discursos XXIV-XXVIII. Las opiniones de Lope y Góngora sobre el vulgo, referidas por Hebrera (pp. 85-86), salen de la Rhythmica (pp. 588-590; véase la nota 28).

28. Una vez más, el refrán de Lope («porque, como las paga el vulgo, es justo / hablarle en necio para darle gusto», vv. 47-48) circula a través de la deformación de la fuente: «El pueblo es necio y por aquesto [aqueso en la Rhythmica] es justo / hablarle en necio para darle gusto» (la cita se emplea para adoctrinar a los oradores: «Consejo es de Lope de Vega para los versos, miren con cuánta más razón será para los sermones», p. 85). 
Heroyda Ovidiana, con los muchos sonetos de comedias que esta obra reúne. La estadística de por sí es significativa hasta cierto punto, pero vale la pena recordar los pesos relativos: se mencionan 13 veces los versos gongorinos (en otra ocurrencia se alude al cordobés, pero el soneto no es suyo ${ }^{29}$ ); Lope aparece ocho veces; los textos de anónimos o «ingeniosos» poetas, siete veces; Pérez de Montalbán, cinco. Se insertan seis pasajes de Luis Ulloa Pereira y seis de Félix Paravicino. A los que siguen: Calderón (4), Tirso (3) el príncipe de Esquilache (3), Bartolomé Leonardo de Argensola (3), Mira de Amescua (3), Quevedo (2) y Antonio de Mendoza (2), Yagüe (2) Josef Navarro (2), Matos Fragoso (2). Por último, el resto de colegas más o menos renombrados.

La simple presencia en el listado, en efecto, no dice mucho, ya que es también relevante la ausencia de algunos grandes nombres de la poesía española, que a veces se rememoran (indirectamente), como Garcilaso y Boscán, pero no se consideran aprovechables. Los únicos poetas antiguos cuyos versos florecen en el Jardín son Pedro de Cartagena (XV) y Francisco de la Torre (XVI), el primero por intermediación gracianesca. Nada de autores tradicionales o cultos de la época renacentista (Herrera, Luis de León, Santa Teresa etcétera), con la salvedad de los épicos y de Argensola. Es, en esto, Hebrera un perfecto seguidor de sus modelos, ya que también Jiménez Patón no puede destacarse por su especial amor hacia el siglo XVI.

Otra cuestión que merece la pena analizar, aunque de forma somera, es la tipología métrico-formal y los géneros presentes. Para el fin que se propone Hebrera, todos los géneros parecen adecuados, justamente por contener, dentro de sus varias encarnaciones, ejemplos de figuras retóricas, sin detenerse demasiado en las estructuras que las albergan. El teatro, para poner un ejemplo, no merece un tratamiento especial o muy atento. Tirso se conoce solo a través de los Cigarrales, mientras que Lope principalmente por sus sonetos (de comedia o autónomos), el Arte cómico y La hermosura de Angélica. El nombre de Calderón se conecta con cuatro piezas -dos espectáculos mitológicos $(E l$ laurel de Apolo, Ni amor se libra de amor) y una comedia (El principe constante; la cuarta cita está sin identificar)- pero faltan las obras cumbre. Restringido también el panorama de los demás comediógrafos, ya que pueden leerse versos de Montalbán, Rojas Zorrilla, Mira de Amescua, Matos Fragoso y Diamante, pero no de Moreto, Vélez de Guevara etcétera. Está casi ausente la epopeya, representada solo por Luis Zapata y su Carlo famoso, Barahona de Soto y Lope, con sus respectivas Angélicas, mientras que prevalece decididamente la lírica. Endecasílabos y octosílabos, según había de esperarse, predominan, y dos formas tradicionales que destacan sobre las demás: el soneto itálico y el romance octosílabo español, ya sea autónoma composición (preferentemente) o bien

29. En este recorrido se han subsanado las atribuciones falsas o imprecisas. En el caso específico de Góngora, se trata del soneto Celos, de quien bien ama, amargo freno, y es el error de atribución el que revela, aquí también, la fuente: Gracián (Discurso XXII) identifica correctamente al autor de la pieza, Jerónimo de Mota, pero es verdad que inmediatamente después habla del 'correspondiente' soneto de Góngora (cf. Alatorre, 1988). La pieza comparece igualmente en la Heroyda ovidiana (pp. 101-111), pero allí su autoría está bien aclarada. 
romance teatral (a veces); esencialmente por sus rasgos poéticos y técnicos, más que por su pertinencia a cierto ámbito genérico. No faltan octavas, canciones de heptasílabos y endecasílabos, redondillas, estrofas de pareados, pero son elementos formales minoritarios. Si el romance resultaba la espontánea vía de hacer versos en la Península, y no produce estupor su presencia, tampoco habrá que admirar la frecuencia con la que nos topamos con sonetos a lo largo de este manual: breves y densos semántica y estilísticamente, las formas prototípicas de la lírica acaban por convertirse en minas casi inagotables de herramientas y recursos retórico-poéticos; especialmente en la producción de personalidades como las de Góngora y Lope (y no solo).

Este primer paseo por las callejas del Jardin termina aquí. La (vasta) variedad de los ejemplos, clasificados por Hebrera en cuanto puros hechos formales, y al tiempo la selectividad con la que obra el franciscano, reduciendo el ya recortado listado de escritores presentes en las fuentes, consigue probablemente el resultado al que aspiraba la operación didáctica: en cierta medida, como tendencia, la esterilización de la antología de poemas, evitando ciertos excesos (el Góngora de las Soledades, las peores hinchazones del estilo de Montalbán y las del 'oscuro' Ulloa Pereira etcétera) y allanando también el terreno, al limitar la extensión de las citas a los pasajes cruciales. Barroco, pero con cierta moderación.

Está claro que en esta retórica se va imponiendo una visión de los poetas que hace hincapié solo en determinados nombres (algunos sinceramente elogiados, como Góngora, Lope y Mendoza; otros apenas recordados como autores de las citas; otros, pocos, dignos de pura mención) y sensibilidades del siglo XVII, de ahí que constituya uno de los últimos eslabones de una cadena de textos teóricos del Seiscientos, todos centrados en la contemporaneidad. Ahora bien, no parece que Hebrera tuviera como principal intención la de eternizar la fama de poetas y obras: los autores que integran el ejemplario del franciscano acaban por constituir un canon, no ya fundado en la valoración estética (muy rara, en las páginas del manual, según se ha visto) o histórica, sino en la forma retórica y la expresión lingüística. Hay que dar la vuelta al punto de vista y observar la modernidad 'científica' del Jardin, que aspira a establecer un canon de figuras, de loci communi, que se asocian a las imágenes y formas poéticas transmitidas por algunos poetae selecti.

Y si a una primera ojeada (confieso que es una impresión) las resonancias directas de esta obra, en las retóricas del siglo siguiente, parecen escasas -la reacción antibarroca ayuda a entender el porqué-, es llamativo, sin embargo, que algunos de los fragmentos citados por Hebrera prolonguen su vida didáctica hasta la Lógica y arte de bien hablar de Josep Pau Ballot i Torres ${ }^{30}$, un compendio para jóvenes, en el que la poesía tiene, a fin de cuentas, poca relevancia.

30. En Barcelona, por Juan Francisco Piferrer, sin fecha (pero es de comienzos del XIX). 


\section{Bibliografía}

Alatorre, Antonio, «Fama española de un soneto de Sannazaro», Nueva Revista de Filología Hispánica, 2, 1988, pp. 955-973.

Artaza, Elena, «Las retóricas barrocas (1660-1650): notas introductorias», en Estudios de filología y retórica en homenaje a Luisa López Grigera, E. Artaza et alii (eds.), Bilbao, Universidad de Deusto, 2000, pp. 45-66.

Blecua, Alberto, "Lope en la Heroida Ovidiana de Alvarado y Alvear», Anuario Lope de Vega, 5, 1999, pp. 3-41.

Blecua, Alberto, «Sebastián de Alvarado y Alvear, el P. Matienzo y Baltasar Gracián», en Estudios de filología y retórica en homenaje a Luisa López Grigera, E. Artaza et alii (eds.), Bilbao, Universidad de Deusto, 2000, pp. 77-127.

Egido, Aurora, "El arte de la memoria y El Criticón», en Gracián y su época. Actas de la I Reunión de flólogos aragoneses, Zaragoza, Institución Fernando el Católico, 1986, pp. 25-66.

Galbarro García, Jaime, «Hacia una catalogación de las retóricas españolas más importantes del siglo XVII. Modelos, tendencias y canon poético», en B. López Bueno (ed.), El canon poético en el siglo XVII, Sevilla, Universidad de Sevilla, 2010, pp. 73-92.

García Bernal, José Jaime, El fasto público en la España de los Austrias, Sevilla, Universidad de Sevilla, 2007.

Latassa y Ortín, Félix de, Bibliotecas antigua y nueva de escritores aragoneses, de Latassa, aumentadas y refundidas en forma de diccionario bibliográfico-biográfico por Miguel Gómez Uriel, Zaragoza, Imprenta de Calixto Ariño, II [H-P], 1885.

Martín Jiménez, Alfonso, "Ramus et l'Université espagnole», en Ramus et l'Université, en Cahier V.L. Saulnier, 21, 2004, pp. 131-153.

Mazzocchi, Giuseppe, "Caramuel e la poesia spagnola. Leggendo la Rhytmica", en Un'altra modernità. Juan Caramuel y Lobkowitz (1606-1682): enciclopedia e probabilismo, D. Sabaino y P. Pissavino (eds.), Pisa, ETS, 2012, pp. 111-126.

Mazzocchi, Giuseppe, «El Góngora de Gracián (con Tesauro a la vista)», Bulletin Hispanique, 2015, en prensa.

Monge, Félix, «Culteranismo y conceptismo a la luz de Gracián» en Homenaje. Estudios de Filología e historia literaria lusohispanas e iberoamericanas, publicados para celebrar el tercer lustro del Instituto de estudios hispánicos, portugueses e iberoamericanos de la Universidad Estatal de Utrecht, La Haya, Van Goor Zonen, 1966, pp. 355-381.

Monge, Félix, "Una retórica aragonesa de fines del siglo XVII», en Gracián y su época. Actas de la I Reunión de filólogos aragoneses, Zaragoza, Institución Fernando el Católico, 1986, pp. 103-115.

Palmer Wardropper, Nancy, «Sebastián de Matienzo y su Heroyda Ovidiana», en A. David Kossof et al. (eds.), Actas del VIII Congreso de la Actas del VIII Congreso de la Asociación Internacional de Hispanistas, Madrid, Istmo, 1986, pp. 711-718.

Pérez Lasheras, Antonio, «La literatura española en la Agudeza de Gracián», Bulletin Hispanique 109-2, 2007, pp. 545-587. 
Rambaldi (de Imola), Benvenuto, Introductio, Comentum super Dantis Aldigherij comoediam Benvenuti De Rambaldis de Imola, curante Jacobo Philippo Lacaita, Florentiae, Barbera, vol. I, 1887.

Rico Verdú, José, La retórica española de los siglos XVI y XVII, Madrid, CSIC, 1973.

Rozas López, Juan Manuel y Quilis, Antonio, «El lopismo de Jiménez Patón: Góngora y Lope en la Elocuencia española en arte», Revista de Literatura, 44-45, 1962, pp. 35-54. 
